\title{
How Rice Likeliness is Associated With Ketones in Urine?
}

\author{
Muhammad Imran Qadir, Aasma Aslam* \\ Institute of Molecular Biology and Biotechnology, Bahauddin Zakariya University, Multan, Pakistan
}

*Corresponding Author: Aasma Aslam, Institute of Molecular Biology and Biotechnology, Bahauddin Zakariya University, Multan, Pakistan

\begin{abstract}
The body produce ketones by burning fats in the short supply of energy in the form of glucose. The pouring of ketones into the urine is known as ketonuria. High level of ketones in urine is the sign of diabetics. The normal range of ketones is usually 1.5-3mmol/L. If higher than normal amount of ketones is present in urine then the person shows some type of symptoms such as dry cool skin, fatigue, high blood glucose concentration. Confusion, abdominal pain and deep breathing. Depending upon the concentration of ketones in urine, the patients show different symptoms like dry mouth, fatigue, fruity smell in urine and breath, urgent need to urination and vomiting. Rice is the cereal crop which is full of starch and carbohydrates. It can provide about $80 \%$ of the daily calories required by the human body. Most of the people are completely dependent on rice rather than wheat. Most of the people think that their diet remains incomplete without rice. The basic purpose of this study is to know about the relationship between urine ketones with rice likeliness. The amount of ketones in urine is determined by urinalysis test. To do this, urine sample was collected from random individuals. Few of them were diabetic patients. Test was performed by dipstick method. There were 100 subjects who participated in this study. These subjects were the students of BZU (Bahauddin Zakariya University Multan Pakistan).
\end{abstract}

Keywords: Ketones, Urine Sample, Rice Likeliness, Test Strips

\section{INTRODUCTION}

When a person does not take sufficient amount of glucose, then his body gets energy by burning fats. This process produces ketone bodies which can be seen in blood or urine of that person. The pouring of ketones into the urine is known as ketonuria. High level of ketones in urine is the sign of diabetics. The normal range of ketones is usually $1.5-3 \mathrm{mmol} / \mathrm{L}$. If higher than normal amount of ketones is present in urine then the person shows some type of symptoms such as dry cool skin, fatigue, high blood glucose concentration. Confusion, abdominal pain and deep breathing. The diabetic patients have greater risk of having high level of ketones in their urine due to insufficient intake of insulin or ineffective dosage of insulin. Moreover, those people who undergo critical situations such as pneumonia, pregnancy, heart attack, alcohol abuse, fasting or high fever have also greater chance of having ketones in urine. Depending upon the concentration of ketones in urine, the patients show different symptoms like dry mouth, fatigue, fruity smell in urine and breath, urgent need to urination and vomiting. The level of ketones in urine can be tested by using test strips which changes its color if ketone level is high in urine. Moreover, further test may carried out according to situations. These test include chest X-ray, CT scan, ECG, blood culture test etc. A patient should check his ketone level when hid blood sugar level is greater than $240 \mathrm{mg} / \mathrm{dl}$ because it shows the deficiency of insulin. If ketones level is high then it is recommended that a person should drink a plenty of water for the fast removal of ketones from urine (1).

Rice is the cereal crop which is full of starch and carbohydrates. It can provide about $80 \%$ of the daily calories required by the human body. Most of the people are completely dependent on rice rather than wheat. The habit of eating rice depends upon several factors such as taking less time to cook, easy to cook, full of nutritional substances, fragrance and taste. Different strains and varieties of rice are available all over the world. However, it cannot grow in some areas due to the shortage of water supply because it is water loving plant. Nowadays researchers are interesting to modify the genetics of this plant and try to make it drought resistant. It is one of the most important crops in the Asian countries. Most of the people think that their diet remains incomplete without rice. Moreover, it can say that rice can fulfill all the nutrients required by the human body for the cellular activities (2). 
The basic purpose of this study is to know about the relationship between urine ketones with rice likeliness.

\section{ATERials AND MethodS}

\subsection{Measurement of Urine Ketones}

The amount of ketones in urine is determined by urinalysis test. To do this, urine sample was collected from random individuals. Few of them were diabetic patients. Test was performed by dipstick method. The strips were dip into the urine sample and dry them for few seconds. After that, the colors of that strip were matched with standard strip and find the difference and values.

\subsection{Project Designing}

There were 100 subjects who participated in this study. These subjects were the students of Bahauddin Zakariya University Multan Pakistan.

\section{RESULTS}

In this study 100 students of Bahauddin Zakariya University of Multan were taken part. They were asked to take their urine sample of early morning because this urine is more concentrated and provide exact determination of solutes. Their urine samples were tested by dipstick method. The results of the present study show that $59 \%$ females have rice likeliness but they do not contain ketones in their urine while $16 \%$ females like to eat rice but ketone are also present in their urine. In case of male, $75 \%$ males show rice likeliness but $24 \%$ have rice likeliness and contain ketones in urine. However, only $1 \%$ males do not like to eat rice but contain ketones in urine. The higher percentage; $59 \%$ of females and $75 \%$ of male, who like to eat rice but do not contain ketones in urine show that ketones in urine is not correlated with rice likeliness.

The results of the present studies are given in the following graph.

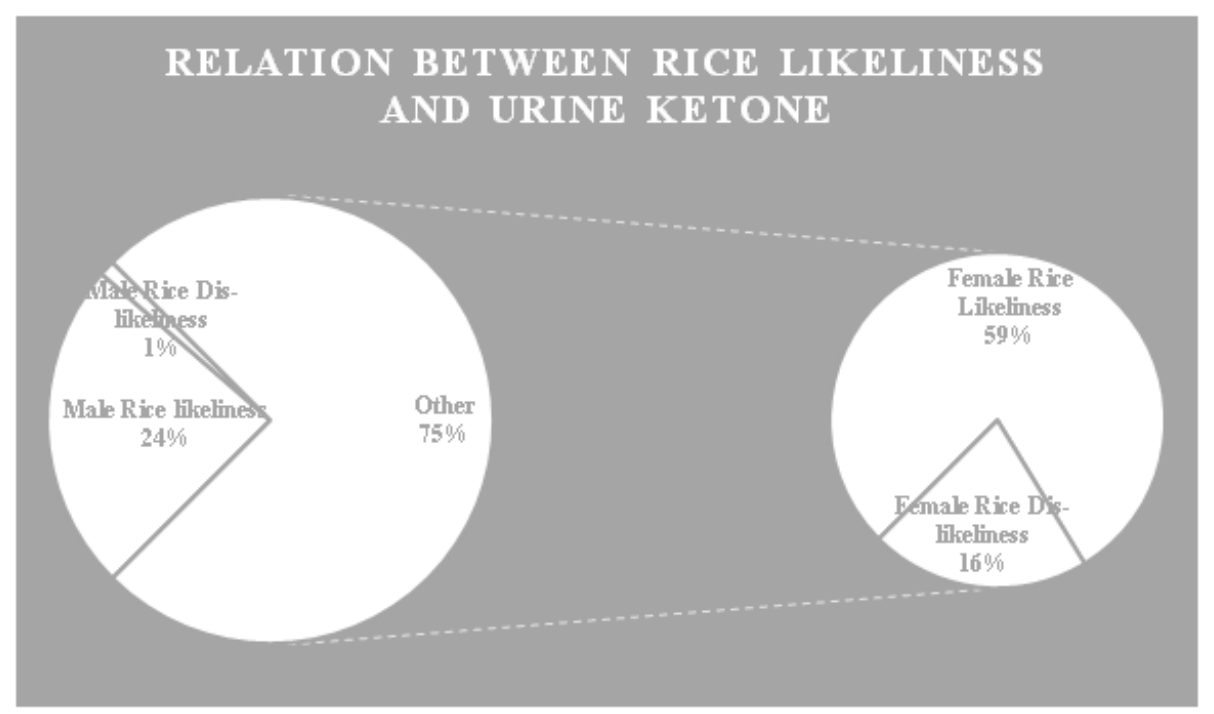

\section{DISCUSSION}

The present studies provide the advancement in recent researches (3-10). This study was carried out to find that urine in ketones is either the result of rice likeliness and eating more rice or not? Previous studies show that the formation of ketones is the result of fat metabolism. It is when body required energy but glucose is not available. These ketones normally seen in blood but they may be in urine in small amount. Knott CD. Studies the changes in urine ketones with respect to fruit availability. The results of this study show that large amount of ketones seen in urine only during the period of shortage of fruit and linked with orangutan which is highly important fat storing material. The orangutan also related to the presence of ketones in urine when fruit are less available. In another study it is reported that Sandra C Van Calcar, Lewis A Barness and Susan R Davidson found that the presence of ketones in urine is directly related with pregnancy condition in women.

\section{CONCLUSION}

The overall results show that there is no association between urine ketones and rice likeliness. 


\section{REFERENCES}

[1] https://www.webmd.com/diabetes/ketones-and-their-tests\#1

[2] Oka, H.-I. 1964. Pattern of interspecific relationships and evolutionary dynamics in Oryza. Pages 7190in International Rice Research Institute, sponsor. Rice Genetics and Cytogenetics. Elsevier, Amsterdam.

[3] Qadir MI, Javid A (2018) Awareness about Crohn's Disease in biotechnology students. Glo Adv Res J Med Medical Sci, 7(3): 062-064.

[4] Qadir MI, Saleem A (2018) Awareness about ischemic heart disease in university biotechnology students. Glo Adv Res J Med Medical Sci, 7(3): 059-061.

[5] Qadir MI, Ishfaq S (2018) Awareness about hypertension in biology students. Int J Mod Pharma Res, 7(2): 08-10.

[6] Qadir MI, Mehwish (2018) Awareness about psoriasis disease. Int J Mod Pharma Res, 7(2): 17-18.

[7] Qadir MI, Shahzad R (2018) Awareness about obesity in postgraduate students of biotechnology. Int J Mod Pharma Res, 7(2): 14-16.

[8] Qadir MI, Rizvi M (2018) Awareness about thalassemia in post graduate students. MOJ Lymphology \& Phlebology, 2(1): 14-16.98-Qadir

[9] MI, Ghalia BA (2018) Awareness survey about colorectal cancer in students of M. Phil Biotechnology at Bahauddin Zakariya University, Multan, Pakistan. Nov Appro in Can Study, 1(3): NACS.000514.2018.

[10] Qadir MI, Saba G (2018) Awareness about intestinal cancer in university student. Nov Appro in Can Study, 1(3): NACS.000515.2018.

Citation: Muhammad Imran Qadir, Aasma Aslam, "How Rice Likeliness is Associated With Ketones in Urine?" International Journal of Research Studies In Biosciences (Ijrsb), Vol. 7, no. 4, pp. 23-25, 2019. http://Dx.Doi.org/10.20431/2349-0365.0704005

Copyright: (C) 2019 Authors. This is an open-access article distributed under the terms of the Creative Commons Attribution License, which permits unrestricted use, distribution, and reproduction in any medium, provided the original author and source are credited. 